\title{
Insulation workers in Belfast. A further study of mortality due to asbestos exposure (1940-75)
}

\author{
P. C. ELMES AND MARION J. C. SIMPSON \\ From the Department of Therapeutics and Pharmacology, The Queen's University of Belfast, Belfast, \\ $B T 97 B L$
}

ABSTRACT A follow-up study of 162 men already working as insulators (laggers) in 1940 has been extended from 1965 to 1975. By the end of 1975 there were 40 survivors when 108 had been expected. Until 1965 there had been an overall excess of deaths; these were due to asbestosis with or without tuberculosis and to alimentary cancer, as well as to bronchial carcinoma and mesothelioma. From 1965 onwards the overall death rate among survivors is not so excessive but there is still a marked excess of deaths from bronchial cancer and mesothelioma. The continued risk of death attributable to malignancy after asbestosis had ceased to contribute directly, does not appear to be caused by any changes which occurred before 1940 in the conditions at work.

In the first studies of insulation workers (laggers) in Belfast, the men who were still at work showed no gross evidence of disability due to asbestos exposure (Wallace and Langlands, 1971; Langlands et al., 1971). However, investigation of a group of men who had been employed in insulation work in 1940 revealed an unexpectedly high mortality (Elmes and Simpson, 1971). The deaths in excess of those expected were due to lung cancer, mesothelioma and gastrointestinal tumours. There were also some due to pulmonary fibrosis in the earlier years. The men had been followed up to the end of 1966 and of the original 170, five were untraced and 98 had died. This paper reports the fate of the survivors and reviews the mortality experience of the whole group to give a clearer picture of the health hazard of the occupation over the period 1940-75.

\section{Methods}

THE POPULATION

The initial total population of Belfast insulation workers (laggers) in 1940 was 170 men. Details of the method of identifying them are given in the previous paper (Elmes and Simpson, 1971). The survivors were seen at two to three-year intervals as part of a continous surveillance of all past and present workers in Northern Ireland whohad worked

Received for publication 22 November 1976

Accepted for publication 20 January 1977 with asbestos. Their family doctors were informed of the possibility of asbestos-induced disease and were asked to keep the authors informed of any serious illness which the workers might develop; they were also warned of the obligation to report subsequent deaths to the coroner.

The cause of death was established as accurately as possible by reviewing the clinical notes and radiographs, and re-examining the post-mortem material where this was available. When there was doubt about the histological diagnosis, material was sent to panels of experts. During the last 10 years the majority of cases were referred to the coroner and the lungs sent intact for fixation and examination by one of the authors (PCE) as well as by the authorised pathologists.

The deaths observed were compared with those expected for men of the same age using figures for the relevant years provided by the Registrar General for Northern Ireland. Differences were regarded as statistically significant if the chance probability was less than one in 20 . The conventional tests used are indicated in the text and in the footnotes to the figures and tables.

\section{Results}

All the data were reanalysed for the purpose of this report. As new information had become available about deaths during the period 1940-66 (Elmes and 
Simpson, 1971) certain discrepancies are apparent between the earlier report and the present one. Information was available on 165 of the original 170 men at the time of the first analysis. Since then information on two additional deaths came to light (one in the 1955-9 period and one in the 1960-4 period) and was added. Five men believed to be alive in 1966 have been lost to follow-up, leaving a basic population of 162 men for analysis, and no women.

In 1940 the men were aged from 16 to 66 years (mean 36.9 yr) and had already worked for up to 35 years (mean $11.3 \mathrm{yr}$ ) as laggers. Table 1 indicates the deaths which have occurred since then, in fiveyear periods, and the source of information on which the diagnosis was based. The information in the first two decades was based mainly on the death certificates but increasingly complete information has been accumulated since then. Table 1 also shows the average age of death in each five-year period. The mean age of the group as a whole must increase five years in each period so that it is difficult to interpret the significance of the rising mean age at death from 49.8 years in $1940-4$ to 65.5 years in 1970-4. The situation is shown diagrammatically as a cumulative comparison in Figure 1, in which the fate of the original 162 men is compared with that of men of the same age in Northern Ireland. Survival amongst the laggers is significantly lower than expected from 1950 onwards $\left(\chi^{2}=33.3\right.$; $\left.P<0.001\right)$. By the end of 1974 only 40 survived when 88 had been expected to survive. The mean age of the survivors is 64.7 years (range $50-81 \mathrm{yr}$ ) at the beginning of 1976 whereas the mean age of the expected surviving group should have been 67.4 years (range 50-87 yr).

A non-cumulative comparison of deaths from all causes compared with the number expected for

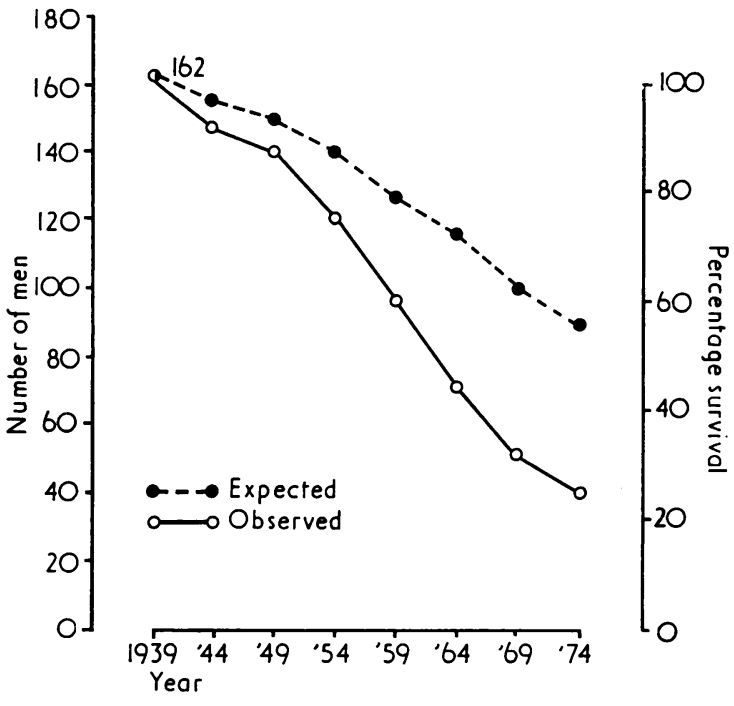

Fig. 1 Survival of insulation workers.

each five-year period is shown in Figure 2. Again the deaths observed and expected are approximately equal for the first two five-year periods, but from 1950 to 1964 the ratio of observed over expected deaths is approximately $3: 1$ and highly significant.

After 1965 the ratio for deaths due to all causes is only 1.5:1 and the difference between observed and expected deaths within each five-year period is not significant. However there is still a significant excess if the two periods are combined $\left(\chi^{2}=7.2 ; \mathrm{P}<0.01\right)$.

\section{CAUSES OF DEATH}

The principal causes of death from malignant and

Table 1 Evidence used in establishing cause of death

\begin{tabular}{|c|c|c|c|c|c|c|c|c|c|}
\hline Evidence & \multicolumn{4}{|c|}{ Number of deaths observed in the period } & $1960-4$ & $1965-9$ & $1970-4$ & 1975 & Total \\
\hline $\begin{array}{l}\text { Complete information including } \\
\text { autopsies }\end{array}$ & 2 & - & 5 & 1 & 9 & 8 & 9 & 一 & 34 \\
\hline $\begin{array}{l}\text { Clinical information with } \\
\text { radiographs and biopsy }\end{array}$ & - & - & 2 & 3 & 7 & 一 & 一 & - & 12 \\
\hline $\begin{array}{l}\text { Clinical information \& radiographs. } \\
\text { No histology }\end{array}$ & 一 & 3 & 15 & 14 & 13 & 3 & 4 & 2 & 54 \\
\hline Death certificate only & 8 & 4 & $4^{*}$ & 3 & 1 & 2 & - & 一 & 22 \\
\hline $\begin{array}{l}\text { Total observed } \\
\text { Total expected } \dagger\end{array}$ & $\begin{array}{l}10 \\
5 \cdot 81\end{array}$ & $\begin{array}{l}7 \\
6 \cdot 50\end{array}$ & $\stackrel{26}{9 \cdot 10}$ & $\begin{array}{l}21 \\
6 \cdot 87\end{array}$ & $\begin{array}{l}30 \\
8.66\end{array}$ & $\begin{array}{l}13 \\
8 \cdot 29\end{array}$ & $\begin{array}{l}13 \\
8 \cdot 45\end{array}$ & $\stackrel{2}{\text { N.A. }}$ & 122 \\
\hline Mean age at death (observed) & $49 \cdot 8$ & $55 \cdot 85_{+}^{+}$ & $54 \cdot 80$ & $58 \cdot 33$ & $59 \cdot 96$ & 67.00 & $65 \cdot 54$ & $65 \cdot 5$ & \\
\hline
\end{tabular}

Mean age in $1940=36.88 \mathrm{yr} ;$ Range $=16-66 \mathrm{yr}$.

Mean age survivors (40) in $1975=64.72 \mathrm{yr} ;$ Range $=50-81 \mathrm{yr}$.

*In one case the year of death was known but the death certificate was untraced.

tExpected number of deaths in those surviving from previous 5-year period (Cf. Fig. 2).

$\ddagger$ Given incorrectly as $\mathbf{5 1 . 4}$ in Elmes and Simpson, 1971.

N.A. = not available. 


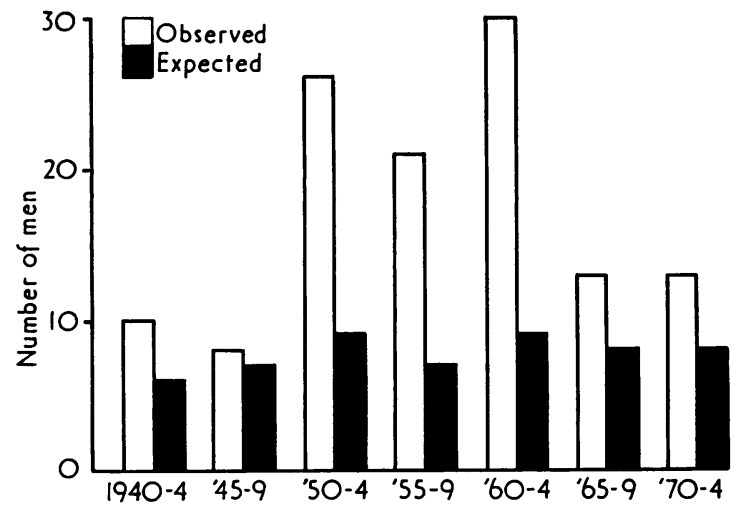

Fig. 2 Deaths from all causes.

non-malignant disease are noted in Table 2 ( $a$ and $b$ ). During the first 10 years only four of the 17 deaths were due to cancer. Between 1950 and 1964 the deaths were equally divided between malignant and non-malignant disease but during the last 11 years 22 of the 28 deaths were due to cancer.

TYPES OF MALIGNANCY

Twenty-four of the respiratory cancers were classified as bronchial carcinoma and eight as definite mesothelioma, but there were in addition 11 cases of respiratory cancer where the evidence was insufficient to differentiate between these two diagnoses. The patient who died with a laryngeal carcinoma between 1970 and 1974 also had a carcinoma of the bronchus. There is no suggestion of an increase in mesothelioma compared with bronchial cancer during the period 1950-75.

Two of the five peritoneal mesotheliomas listed in Table 2a were fully proved but in three there was a possibility of a primary alimentary tumour. There was also a death from alimentary cancer described as due to carcinomatosis peritonei which could not be attributed to a specific alimentary site, and two others which were classified as carcinoma of stomach and colon when the evidence was insufficient to rule out a peritoneal primary. Therefore both in the respiratory and in gastrointestinal cancers there is the difficulty of differentiating between mesothelial and epithelial tumours.

In order to determine more precisely the excess mortality from cancer, a non-cumulative comparison was made between the deaths occurring during each five-year period of the survivors up to that time and an age-matched estimate for the general male population of Northern Ireland. Figure 3 shows the results for all types of cancer. Although the observed deaths are in excess of the expected deaths throughout the whole period, the difference becomes highly significant in the period 1950-54 (absolute probability <0.003). From 1950 onwards the ratio of observed to expected cancer deaths averages 7:1. There is no evidence of the decline in risk shown in the overall mortality (compare Fig. 2 with Fig. 3).

In the majority of cases the deaths from cancer in excess of those expected were respiratory in origin, either bronchial cancer or pleural mesothelioma (Fig. 4). Between 1950 and 1954 the ratio of observed to expected deaths from respiratory cancer is 18:1 and the difference is highly significant (absolute probability <0.03). For the whole of the period 1950-75 it remains at an average of 15:1 and shows no evidence of a declining risk during the last 10 years. Cancers of the gastrointestinal tract and peritoneal mesotheliomas (Table 2) account for the remaining excess of deaths from cancer over the predicted number, but only one gastrointestinal cancer has been seen during the last 10 years. Numbers are too small to estimate the relative risk of other cancers in these men.

Table 2a Malignant causes of death

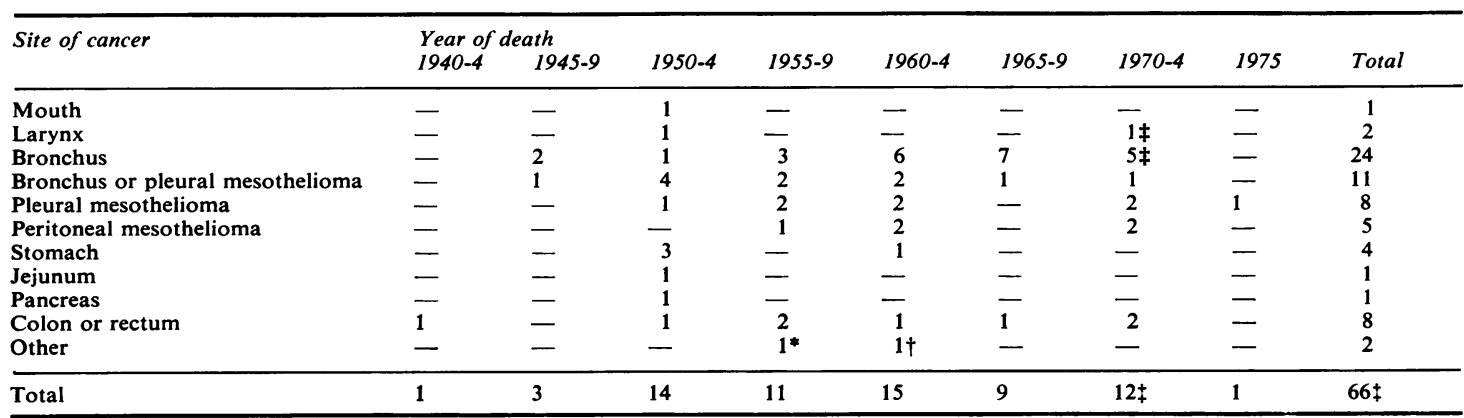

* 1 case of secondary adenocarcinoma of the liver, primary site undetermined.

+1 case of lymphosarcoma of the pleura in a patient with asbestosis.

fOne patient with carcinoma of the larynx also had a carcinoma of the bronchus. 
Table $2 \mathrm{~b}$ Non-malignant causes of death

\begin{tabular}{|c|c|c|c|c|c|c|c|c|c|}
\hline Type of disease & \multicolumn{8}{|c|}{ Year of death } & Total \\
\hline \multicolumn{10}{|l|}{ Respiratory } \\
\hline Asbestosis* & 2 & - & 2 & 4 & 5 & 2 & - & 1 & 16 \\
\hline Asbestosis with tuberculosis & 1 & 1 & 1 & - & - & - & - & - & 3 \\
\hline Tuberculosis alone & 1 & 2 & - & - & - & - & - & - & 3 \\
\hline Pneumonia etc. $\dagger$ & 4 & - & 2 & 2 & - & 2 & 1 & - & 11 \\
\hline \multicolumn{10}{|l|}{ Cardiovascular } \\
\hline Coronary disease & 1 & 1 & 3 & 3 & 3 & - & - & - & 11 \\
\hline Rheumatic heart disease & - & - & 1 & - & 1 & - & - & - & 2 \\
\hline Cerebral & - & - & - & 1 & 2 & - & - & - & 3 \\
\hline Other vascular & - & - & 1 & - & 3 & - & - & - & 4 \\
\hline Other causes & - & - & 2 & - & 1 & - & - & - & 3 \\
\hline Total non-cancer & 9 & 4 & 12 & 10 & 15 & 4 & 1 & 1 & 56 \\
\hline
\end{tabular}

*Patients are classifled as dying of asbestosis when they are known to have suffered from cor pulmonale due to pulmonary fibrosis although infection may have been the precipitating cause of death.

†Patients dying of a chest infection with no evidence that pulmonary fibrosis contributed.

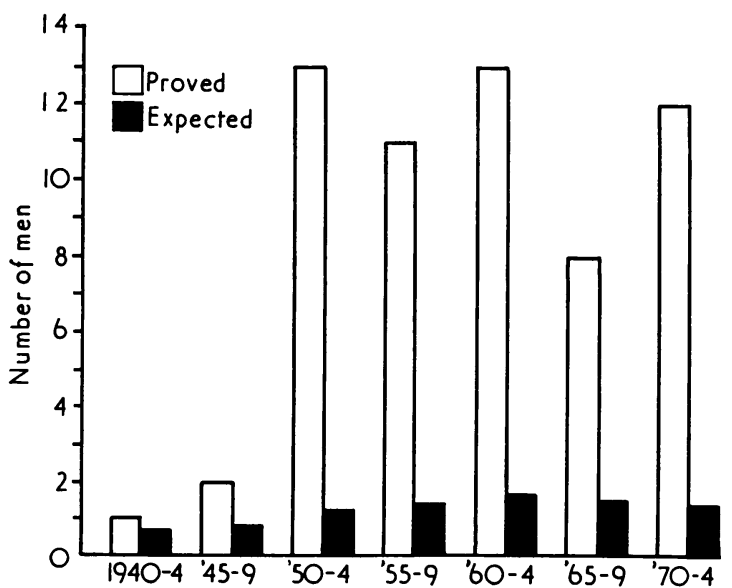

Fig. 3 Deaths from all types of cancer.
NON-MALIGNANT CAUSES OF DEATH

Table $2 \mathrm{~b}$ shows that two of the 13 deaths due to nonmalignant disease which occurred before 1950 were attributed to heart disease, and the rest to respiratory disease; of these 11 respiratory deaths, two were attributed to asbestosis alone, two to asbestosis complicating tuberculosis and three to tuberculosis alone. In only one of these cases (tuberculosis with asbestosis) was there histological or bacteriological confirmation of the diagnosis. In the rest there is evidence of chronic lung disease which may also have been present in the four cases attributed to pneumonia alone. The last patient with tuberculosis complicating asbestosis died in 1952, although active tuberculosis was found at autopsy in a patient dying with carcinoma of the lung in 1971. Asbestosis continued to be an important cause of death until 1964. Between 1950 and 1964 there were 52 more

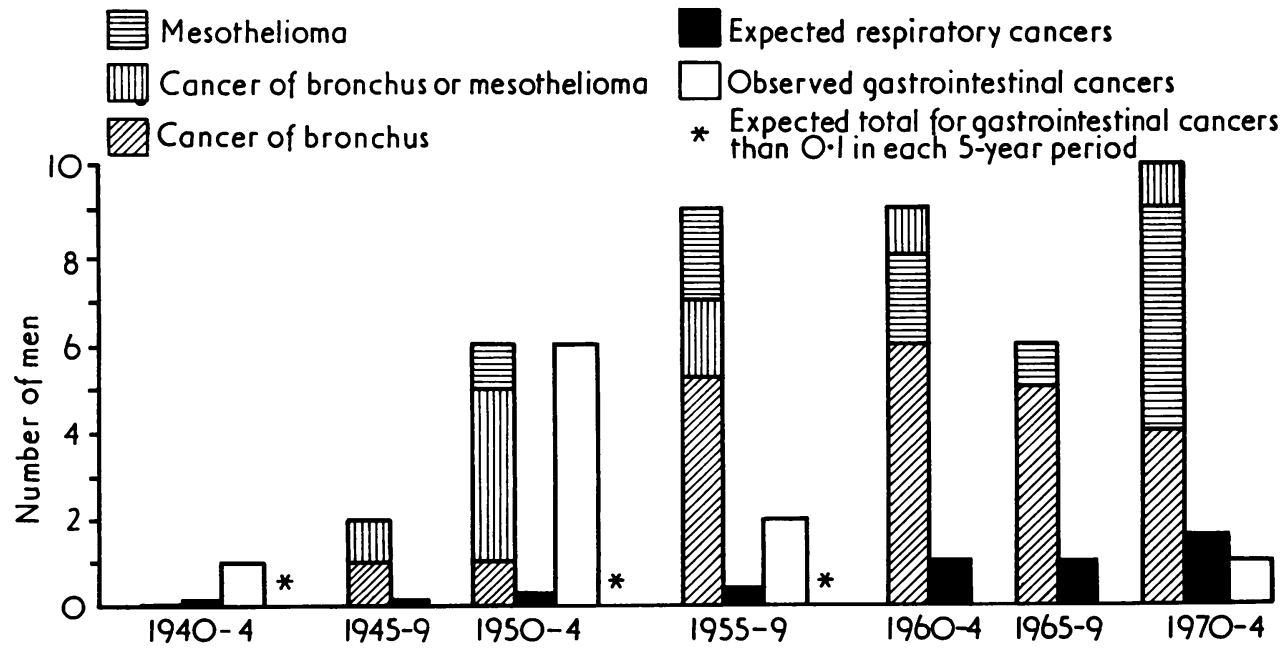

Fig. 4 Types of cancer in asbestos workers. 


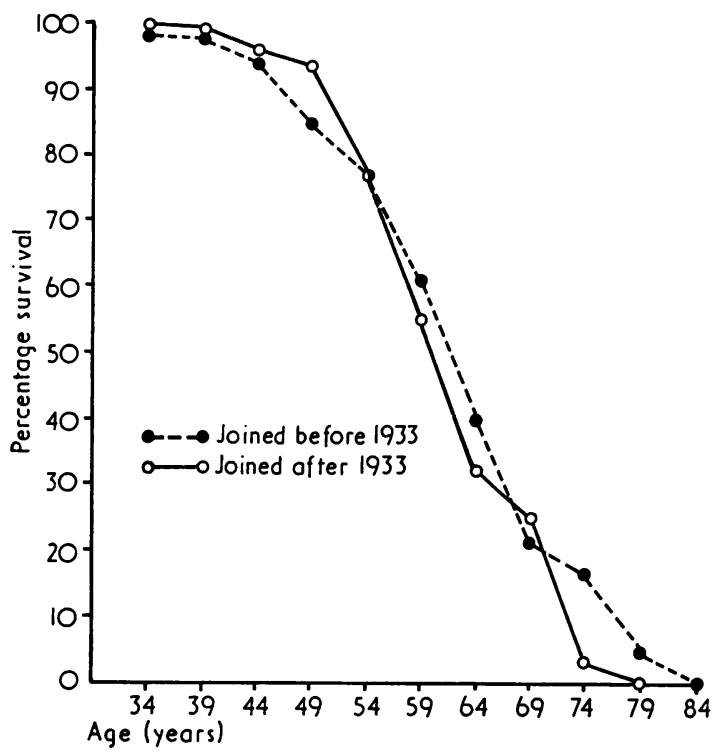

Fig. 5 Survival and date of starting work.

deaths than expected, from all causes (Fig. 2). Over the same period there was an excess of 35 deaths caused by cancer of all types, leaving an excess of 17 attributable to non-malignant disease. It is perhaps a coincidence that, during that period, 17 of the deaths were attributed to asbestosis with or without tuberculosis. After 1964 the excess deaths are entirely attributable to malignant disease.

EVIDENCE OF CHANGING RISK

In Figure 1 the survival of the whole group is compared with that of men from Northern Ireland. In order to determine whether certain variables were important in determining the excessive mortality, the exposed population was divided about the relevant mean and the experience of the two groups of 81 men compared in a similar manner.

a) Date of starting work (dividing year 1933) to determine whether conditions in the early years were sufficiently different from those which existed later to alter the risk. The curves (Figure 5) show no evidence of difference.

b) Age of starting work (dividing age 25 years old) to determine whether first exposure when young produced a different risk from delayed first exposure. The curves showed no difference.

c) Duration of exposure (mean 29 years) was more difficult to analyse because many men remained at work until they died; therefore early death was associated with short exposure. Even when deaths before the age of 45 (16 years until school-leaving plus 29 years' exposure) were disregarded, mortality experience for those with less than 29 years' exposure was greater than for those with more than 29 years' exposure (Figure 6). Table 3 shows that workers who failed to complete 29 years' exposure suffered a relative excess of deaths due to asbestosis with or without complicating tuberculosis. Those who survived more than 29 years' exposure showed a relative excess of deaths due to asbestos-related cancer.

Had these simple tests for changing risk shown a real trend suggesting either an improvement in working environment or evidence of a dose-response relationship, further detailed analysis would have been indicated.

\section{SMOKING}

There were five non-smokers in the whole group; two are still alive aged 61 and 62 years, and one has died of a cerebral embolus. The other two have died of malignant disease but in one case the diagnosis is either a pleural mesothelioma or bronchial carcinoma and the other either a peritoneal mesothelioma or carcinoma of the rectum.

\section{Discussion}

The follow-up of a group of men until they have all died should give a complete picture of their occupational hazard. Difficulties can arise with the statistical interpretation of the results especially if the numbers are small. Because it is difficult to extend such studies beyond a single factory or town, unknown local factors other than the work en-

Table 3 Duration of exposure to asbestos, and cause of death

\begin{tabular}{|c|c|c|c|c|c|c|c|}
\hline \multirow[t]{2}{*}{ Exposure } & \multirow{2}{*}{$\begin{array}{l}\text { Respiratory cancer or } \\
\text { mesothelioma }\end{array}$} & \multirow[t]{2}{*}{ Other cancers } & \multirow{2}{*}{$\begin{array}{l}\text { Asbestosis and } \\
\text { asbestosis with } \\
\text { tuberculosis }\end{array}$} & \multirow{2}{*}{$\begin{array}{l}\text { Tuberculosis alone } \\
\text { and other causes }\end{array}$} & \multicolumn{2}{|l|}{ Totals } & \multirow[t]{2}{*}{ Total } \\
\hline & & & & & Dead & Alive & \\
\hline $\begin{array}{l}29 \text { yr or less } \\
\text { Over } 29 \mathrm{yr}\end{array}$ & $\begin{array}{l}18 \\
31\end{array}$ & $\begin{array}{l}9 \\
8\end{array}$ & $\begin{array}{r}13 \\
6\end{array}$ & $\begin{array}{l}24 \\
13\end{array}$ & $\begin{array}{l}64 \\
58\end{array}$ & $\begin{array}{l}17 \\
23\end{array}$ & $\begin{array}{l}81 \\
81\end{array}$ \\
\hline Total & 49 & 17 & 19 & 37 & 122 & 40 & 162 \\
\hline
\end{tabular}

$\chi^{2}$ for causes of death $=9.084$; three degrees of freedom $0.05>P>0.02$.

$x^{2}$ between total frequency of death $=0.83$; one degree of freedom $0.5>P>0.3$. 


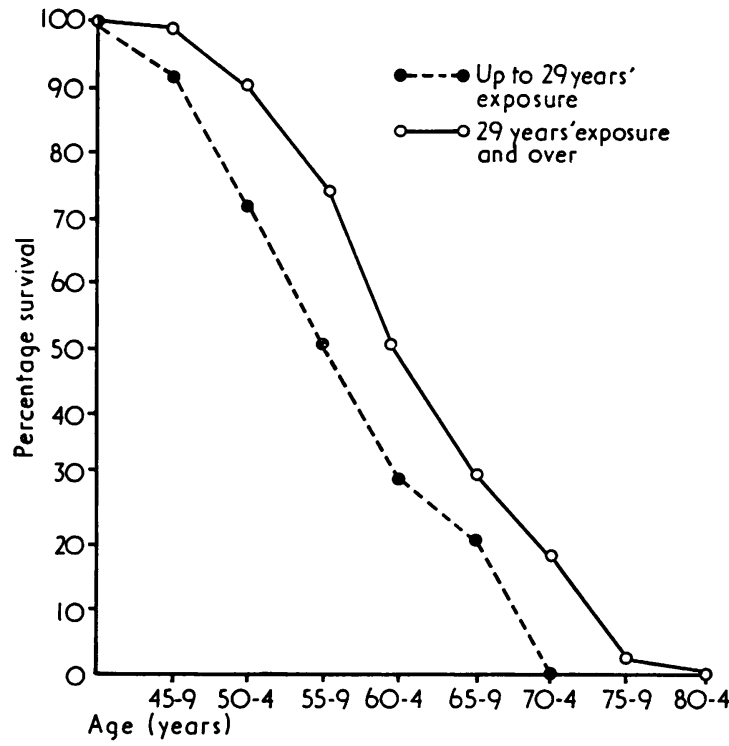

Fig. 6 Effect of duration of exposure on percentage survival by age. Deaths occurring before the age of 45 years are excluded (see text).

vironment may be present. There are few published studies of this sort, therefore their value is unproved.

The study reported here is still not complete in that only 122 of the 162 men are dead, 24 more than had died at the time of the first report nine years earlier (Elmes and Simpson, 1971). Has the additional information altered the outline of the hazard described in the first report, and will following the remaining $\mathbf{4 0}$ men change the outline?

The initial study demonstrated that the men were dying prematurely; the new information shows that although this excessive mortality has continued it may be less serious. By the end of 1975 there had been 122 deaths when only 54 had been expected. From 1965 onwards the death rate for cancer, especially mesothelioma and lung cancer, remained considerably in excess of that expected. The death rate from other causes was relatively low, even from non-malignant lung disease. There was no evidence to show that the survivors were at a continued serious risk of dying from asbestosis (with or without tuberculosis) or from alimentary cancer.

The conditions of work for insulation workers changed dramatically in the early 1960s when the hazards of asbestos were fully appreciated. Since 1965 very little asbestos, other than in the form of Marinite board, has been used in ships made in Belfast. Asbestos insulation has been used less and less in industry outside the shipyard, but there remains the problem of removing old insulation. This work is done by insulation workers (laggers) but with reluctance and circumspection. Although this change in working conditions has been too late to affect the overall mortality of this group of men so far, changes in the causes of death have occurred. These changes may have been due to changes in working conditions in earlier years or to the fact that the group as a whole is ageing. Splitting the working group into those who started work before 1933 and those who started after 1933 failed to show any evidence of a change in risk at that time. The earlier study showed no evidence of a change in risk before 1933, and because of the exclusion from the study of men starting work after 1940 changes since then cannot be evaluated. A running analysis of mortality for all the insulation workers in Belfast, irrespective of when they started work, is necessary to evaluate changes in the hazard. The gradual disappearance of asbestosis as a primary cause of death since 1965 is suggestive of a reduction in the level of exposure some years earlier which was not sufficient to affect the overall mortality.

The decline of gastrointestinal cancer as a significant cause of excess mortality from 1960 may also be due to a reduction in the level of exposure some years earlier. The mean age of the men who died of a gastrointestinal cancer was 61 years and ranged from 49 to 76 years. The survivors in 1960 were still well within this susceptible age range.

It is unlikely that a follow-up of the remaining 40 will reveal any new hazard. However it should enable quantification of the risk of carcinoma of the lung and mesothelioma. It should also help to show whether the risk of asbestosis and alimentary cancer is no longer significant. It is not possible to estimate in retrospect the dust concentrations and types of asbestos to which these men were exposed. The hazard appears comparable to that which was present in certain English asbestos factories before the introduction of the 1933 regulations (Knox et al., 1965; Newhouse, 1969). The pattern of change in cause of death is similar to that described by Smither (1965). This type of study is of little value in the establishment of a safety standard because it has been obvious for many years that the conditions under which these men used to work were far too dangerous. However this study does indicate that mixed exposure of this sort carries a significant risk of bronchial cancer even when asbestosis is no longer a significant cause of death. For mixed exposure a standard based on the prevention of asbestosis may not provide adequate protection against neoplasia.

\section{References}

Elmes, P. C., and Simpson, Marion J. C. (1971). Insulation workers in Belfast. 3. Mortality 1940-66. British Journal of Industrial Medicine, 28, 226-236. 
Knox, J. F., Doll, R. S., and Hill, I. D. (1965). Cohort analysis of changes in incidence of bronchial carcinoma in a textile asbestos factory. Annals of the New York Academy of Sciences, 132, 526-535.

Langlands, Jean H. M., Wallace, W. F. M., and Simpson, Marion J. C. (1971). Insulation workers in Belfast. 2. Morbidity in men still at work. British Journal of Industrial Medicine, 28, 217-225.

Newhouse, M. L. (1969). A study of the mortality of workers in an asbestos factory. British Journal of Industrial Medicine, 26, 294-301.

Smither, W. J. (1965). Secular changes in asbestosis in an asbestos factory. Annals of the New York Academy of Sciences, 132, 166-181.

Wallace, W. F. M., and Langlands, Jean H. M. (1971). Insulation workers in Belfast. 1. Comparison of a random sample with a control population. British Journal of Industrial Medicine, 28, 211-216. 